\title{
The Optimal Trade Bargaining Strategies in the Negotiation of DDA*
}

\author{
Young-Han Kim**
}

August 2003

\begin{abstract}
This paper examines the optimal trade negotiation strategies in the trade negotiation involving multi-parties such as Doha Development Agenda, which is characterized by asymmetric multiple negotiators with multi-trade issues. Due to the consensus rule, which is the formal decision making rule of WTO, bilateral bargaining formula is often taken simultaneously with the multilateral bargaining formula. We demonstrate that the large economy, which might pose a fundamental objection, prefers the sequential bilateral negotiation, while multilateral negotiation from the initial stage of bargaining is welfare dominant for small economies. World welfare is also improved with the adoption of multilateral negotiating regime from the initial stage of negotiation compared to bilateral negotiation.
\end{abstract}

Key Words: Optimal Negotiation Strategies, Multilateral Bargaining, Consensus Rule of WTO

JEL Classification: F12; F13; F15

* This paper is prepared for the presentation at ETSG 2003 meeting at Madrid. Many valuable comments by the participants of the economics workshop of Sungkyunkwan University and Conference of the Association of Trade and Industry Studies are deeply appreciated. This work was supported by Korea Research Foundation Grant (KRF-2002-041-B00114).

** Department of Economics, Sungkyunkwan University, Seoul, 110-745, South Korea E-mail: kimyh@skku.edu, Tel; 82-2-760-0615, Fax: 82-2-744-5717 


\section{Introduction}

The dramatic agreement to launch Doha Development Agenda, as a new multilateral trade negotiation forum of WTO at Doha, Qatar in 2001 significantly reduced the fear of the deadlock of the international trading regime. With the launch of DDA, many critical issues and agenda are under negotiation with various types of bargaining formula depending on the characteristics of bargaining agenda and negotiating parties. South Korea, for example, is supposed to make deals on market opening in agricultural commodity markets and various service sector markets. In addition, multilateral negotiation to set up more rigorous international rules of Anti-dumping measures and other trade remedy measures is strongly supported by many Newly Industrialized countries in addition to Korean manufacturers. Depending on the characteristics of issues, the market power of negotiating parties varies. South Korea commands market power in several manufactured goods such as semi-conductors and shipbuilding industries, while it is a price taker in agricultural commodities and other service sector industries.

All these features of DDA of WTO can be characterized as a negotiation over multiple issues between asymmetric multiple negotiation parties. Moreover, the major decision-making rule of WTO is the consensus rule, which is different from the majority rule or the unanimity rule. According to the consensus rule, a multilateral agreement is reached at WTO when no delegation physically present in the Council has a fundamental objection on an issue. ${ }^{1}$ This consensus rule ensures that only decisions, on which there is no major opposition and consequently which have good chances of being implemented, are made. Due to the consensus rule, a bilateral bargaining formula is often taken simultaneously with the multilateral bargaining formula to address any possible 'major opposition.'

\footnotetext{
${ }^{1}$ Refer Hoekman \& Kostecki (2001) for the more detailed discussion on the consensus rule.
} 
The analysis of the equilibrium structure in international trade negotiation has its origin in classic works of Nash (1950) and Rubinstein (1982). The application of these classic axiomatic and extensive bargaining theories into international trade negotiation analysis can be categorized into 3 groups. The first group is composed of Dixit (1987), Bagwell and Staiger (1990) and Riezman (1991), who examine issues of trade cooperation by way of two-country model in which governments choose trade policies in a repeated-game setting. They show that there are multiple bargaining equilibria including inefficient ones, and suggest that a multilateral trading regime such as WTO may help countries to coordinate on more efficient equilibria.

The second group focuses on the role of multilateral trading regime focusing on the information-gathering role of WTO led by Hungerford (1991), Kovenoch and Thursby (1992) and Maggi (1999). This approach focuses on the information-gathering role of WTO, that enables to discern between true violations of the agreement, thus facilitating the use of a bilateral reputation mechanism to support cooperation.

The third group examines the role that private information plays in the operation of trade policies. Jensen and Thursby (1990) analyze a non-cooperative trade policy game, while the operation of trade policies in a cooperative setting were analyzed by Feenstra and Lewis (1991), Bac and Raff (1997), and McCalman (2002).

Finally, the analysis on trade negotiation among asymmetric countries is addressed by Mayer (1981), Kennan and Riezman (1988), McLaren (1997), Furusawa (1999), and Park (2000). Especially, Furusawa (1999) has shown that more patient countries gain more from negotiation when the time lag in the negotiation is short, and Park (2000) demonstrates that direct transfer might improve the welfare effect in negotiation among asymmetric countries based on bilateral bargaining formula.

While the earlier studies have significantly extended the understanding of international trade negotiation mechanism, the equilibrium structure of multilateral trade negotiation among asymmetric countries has not been addressed yet. In addition, the comparative welfare analysis of bilateral and multilateral negotiation regime among 
asymmetric countries has not been tried yet. The aim of this paper is to examine these unexplored issues focusing on the asymmetry in terms of country size, which will have asymmetric impacts on each country's role and influence in the WTO negotiation process under the consensus rule.

The purpose of this paper is to examine the optimal negotiation strategies in the New Round Trade Negotiation, which is characterized by asymmetric multiple players. ${ }^{2}$ Based on the model which focuses on the asymmetry of negotiators in terms of market size and the resulting asymmetry in negotiating power, we demonstrate that the large economy prefers the bilateral trading regime, while multilateral bargaining regime is welfare dominant for a small economy. World welfare is also improved with the adoption of multilateral negotiating regime.

This paper is organized as follows. Section 2 explains the model structure to analyze the optimal bargaining strategies between asymmetric countries, and the non-cooperative multilateral trade policy game, which is equivalent to the trade warfare state, is discussed as a benchmark discussion. In section 3, the equilibria under the global trade policy cooperation, the multilateral trade policy cooperation under the consensus rule, and the bilateral trade policy cooperation are examined. Section 4 examines the optimal trade negotiation strategies for each different type of country based on the equilibria obtained in section 3 and section 5 discusses the policy implications and concludes.

\footnotetext{
2 The major feature of Doha Development Agenda of WTO is that i) it is a negotiation between asymmetric multiple negotiators, and that ii) it is a single undertaking of multi-trade issues based on issue-linkage strategies. In that context, the analysis on the equilibrium issue-linkage strategy should be a germane part of the DDA analysis. This paper, as an initial study to examine the equilibrium negotiation strategies among asymmetric multilateral negotiators, focuses on the multilateral negotiation on a single issue, tariff negotiation issue. The analysis of the equilibrium issue-linkage strategy in multilateral negotiation would be a major task of future studies as an extension of present model analysis.
} 


\section{The Model.}

Assume that there is one large country, $A$, and three small countries $B, C, D$, and the inverse demand function of each country is as follows: $P_{i}=a-b Q_{i}$ where $i=A, B, C, D$ and $Q_{i}$ is the total quantity demanded in market $i$. There is one representative firm in each country. The inverse demand function in country $A$ is given as follows: $P_{A}=a-b\left(q_{A}+\chi_{B A}+\chi_{C A}+\chi_{D A}\right)$ where $q_{A}$ is the output of firm $A$ for the home market and $x_{B A}$ is the output produced by the firm in country $B$ to export to country $A$.

When we assume that the marginal production cost is same among four countries, the profit function of firm $A$ is described as:

$\prod_{A}=\left(P_{A}-c\right) q_{A}+\left(P_{B}-c-t_{B}\right) \chi_{A B}+\left(P_{C}-c-t_{C}\right) \chi_{A C}+\left(P_{D}-c-t_{D}\right) \chi_{A D}$

where $t_{i}$ is the import tariff imposed by country $i$.

The inverse demand functions and the profit functions for $B, C, D$ are defined in the same way respectively. The government of each country decides its trade policy, i.e., the import tariff level, and then each firm decides its output strategy after it observes the trade policies. In this two-stage game, the equilibrium market condition can be obtained by backward induction.

With the consensus rule as the formal decision making rule of WTO, it is assumed that a multilateral agreement is reached only when there is no fundamental objection from a major trading country. To consider the effect of the consensus rule in the model, we assume that among four countries, country $A$ is a large country which might pose a major opposition while country $B, C, D$ are relatively small countries. In addition, when two small countries form a coalition, the coalition might raise a fundamental objection while each individual small country has no chance of offering the major opposition. Therefore, a multilateral trade agreement under the consensus rule is reached only when there is no objection from country $A$ or from any coalition of small countries. $^{3}$

3 Every country in this model has the market power in the sense that even the country with a small 
We assume that each country simultaneously decides the optimal tariffs. ${ }^{4}$ It is assumed that the tariff rate of each country includes the impact of non-tariff barriers. Therefore, even with the different tariff rates with respect to different countries, the Most Favored Nation clause is not violated. In the multilateral trading system, the cooperative trade regime can be supported only when the large economy joins the multilateral agreement while the cooperation from the every small country is not a necessary condition under the consensus rule.

\section{The non-cooperative trade policies under multilateral negotiation regime}

The case of non-cooperative multilateral trader is examined when technologies are symmetric as a benchmark discussion, while the market size of country $A$ is assumed to be significantly larger than those of small countries. ${ }^{5}$ When each country's trade policy is decided in a non-cooperative way, the non-cooperative Nash tariffs of country $A, B, C, D$ under the simultaneous decision-making process are decided in the following way. By backward induction, the equilibrium output of the firm in each country is determined first. The best response functions of firm $A$ in each market are derived from the profit maximization problem with respect to output levels as strategic variables. The best response functions of firm $B, C, D$ are derived in the same way. Then, the four representative firms' equilibrium outputs in country $A$ are decided as follows by solving four firms' reaction functions in country $A$ simultaneously assuming the marginal cost $(c)$ to be 0 for the simplicity of exposition: ${ }^{6}$

market size can influence the market price due to the oligopoly market structure in which the equilibrium price is derived from the best response function of each country. Therefore, discussion of the consensus rule and 'the major opposition' in the context of 'market power' is improper in this model. Hence it is assumed that the country with a largest market size and coalition between any two countries might pose a fundamental objection in the context of the consensus rule.

${ }^{4}$ The optimal tariffs are examined in each case of trade negotiation regime including the case when the trade policy coalition is formed. The case of global trade cooperation, multilateral trade cooperation, and the bilateral trade cooperation are the cases of coalition only differing in the number of coalition members. The case of global trade warfare in this paper denotes the case when there is no coalition in the process of trade negotiation.

${ }^{5}$ The market size of country $A$ can be described by the vertical intercept of the inverse demand function in country $A$, i.e., $a$. When we denote the intercept of inverse demand functions of small countries as 1 for simplicity, the asymmetry in market size can be described as a $>1$.

6 The concavity of the objective function of the representative firm and the government is shown as 


$$
q_{A}=\frac{a+3 t_{A}}{5 b}, \quad \chi_{B A}=\frac{a-2 t_{A}}{5 b}, \chi_{C A}=\frac{a-2 t_{A}}{5 b}, \quad \chi_{D A}=\frac{a-2 t_{A}}{5 b}
$$

With symmetric technologies and demand functions, the equilibrium output in country $\mathrm{B}$ and $\mathrm{C}$ are respectively:

$$
\begin{aligned}
& q_{B}=\frac{a+3 t_{B}}{5 b}, \quad \chi_{A B}=\frac{a-2 t_{B}}{5 b}, \chi_{C B}=\frac{a-2 t_{B}}{5 b}, \quad \chi_{D B}=\frac{a-2 t_{B}}{5 b} \\
& q_{C}=\frac{a+3 t_{C}}{5 b}, \quad \chi_{A C}=\frac{a-2 t_{C}}{5 b}, \chi_{B C}=\frac{a-2 t_{C}}{5 b}, \quad \chi_{D C}=\frac{a-2 t_{C}}{5 b} \\
& q_{D}=\frac{a+3 t_{D}}{5 b}, \quad \chi_{A D}=\frac{a-2 t_{D}}{5 b}, \chi_{D C}=\frac{a-2 t_{D}}{5 b}, \quad \chi_{C D}=\frac{a-2 t_{D}}{5 b}
\end{aligned}
$$

Each firm sells in its domestic market by the amount of $\frac{a+3 t_{i}}{5 b}$, and in three foreign markets by the amount of $\frac{a-2 t_{j}}{5 b}$ in equilibrium where $t_{i}$ represents the tariff rate of the home country and $t_{j}$ is the tariff rate imposed by the foreign country.

The social welfare function of the country $A$ is defined as the summation of the consumer surplus, the producer surplus, and the government surplus, i.e., the import tariff revenue:

$$
S W=C S+P S+G S=\int_{P^{*}}^{a} D(P) d P+\prod_{A A}+\prod_{A B}+\prod_{A C}+\prod_{A D}+t\left(\chi_{B A}+\chi_{C A}+\chi_{D A}\right)
$$

With the continuously quasi-concave well-behaving social welfare function, the optimal trade policy for country $A$ under the non-cooperative trade regime is derived as a solution of the first order condition of the social welfare maximization problem with respect to the tariff as follows: $t_{A}{ }^{*}=3(a-c) / 11=3 a / 11$ where $c=0 .^{7}$ When each country's trade policy is decided in a non-cooperative way, the non-cooperative

follows even with the zero cost assumption: s.o.c. $=\frac{\partial^{2} \prod_{A}}{\partial q_{A}{ }^{2}}=-2 b<0$, s.o.c. $=\frac{\partial^{2} S W_{A}}{\partial q_{A}{ }^{2}}=-b<0$. This concavity of the objective function is obtained from the assumption of the Cournot fashion competition with the downward sloping demand function. However, the introduction of the asymmetric cost structure into the model would provide more abundant insights, which would be the task of the future study.

${ }^{7}$ We check the case when technologies are symmetric, i.e., $c=0$, while the market size of $A(a)$ is significantly larger than those of small countries, which is assumed to be 1 without loss of generality: $\mathrm{a}>1$. 
Nash tariff of country $A, B, C, D$ under simultaneous decision making are respectively: $3 a / 11,3 / 11,3 / 11$, and 3/11. The reason that each country's tariff is independent from each other country's market size is that, three markets are separated markets. In this non-cooperative trading regime, the social welfare of country $A, B, C, D$ are obtained by substituting the equilibrium tariffs and equilibrium outputs into the social welfare functions respectively as follows: $\frac{3\left(2+33 a^{2}\right)}{242 b}, \frac{103+2 a^{2}}{242 b}, \frac{103+2 a^{2}}{242 b}$, and $\frac{103+2 a^{2}}{242 b}$, leading to the world welfare level of $\frac{315+105 a^{2}}{242 b}$. These payoffs and optimal tariffs from the non-cooperative trade regime are equivalent to the cases of the trade warfare state.

\section{Equilibria under the cooperative trade regime}

\subsection{Global trade policy cooperation with the unanimity rule}

There are three different types of negotiation formula to reach at a cooperative trade regime. The first type is the global trade policy cooperation with the unanimity rule, in which all countries abide by the cooperative trade policies without exemption. The second way to reach at a cooperative trade regime is multilateral trade negotiation based on the consensus rule. Reflecting the characteristics of the consensus rule, which assume that an agreement is reached when there is no fundamental objection, a multilateral trade agreement can be achieved when at least the large economy, $A$ and the two of the small countries reach an agreement due to our assumption that a coalition between small countries might raise a 'fundamental objection'. In this multilateral agreement, at least three countries including the large country should abide by the cooperative trade policies simultaneously. The policy commitment for free trading regime is credible only when it satisfies the self-enforcing condition because we assume there is no credible international enforcement mechanism as observed in the reality. The third type of negotiation to reach a cooperative trade regime is the bilateral negotiation. 
If the trade cooperation is arranged by bilateral negotiation just between two countries while two other countries keep non-cooperative strategies, the trade regime will be a partially cooperative regime. ${ }^{8}$ We examine which trade negotiation regime among three types of trade policy cooperation is more efficient in terms of welfare effects for small and large countries, and the world welfare level.

First, we check the case of global trade policy coordination in the unanimity fashion. The equilibrium under global trade policy cooperation is derived in the same way as in the case of non-cooperative multilateral regime based on backward induction. The reaction functions of four representative firms are derived, and then the firms' equilibrium outputs are obtained as solutions of four simultaneous equations of reaction functions. Then, by substituting these equilibrium outputs into the world welfare maximization problem with respective to the coordinated tariff, the optimal trade policy for each country is obtained as a specific import subsidy by the amount of $(a+3) / 12$. Then, with the substitution of the optimal subsidy into the welfare function, the world welfare level of the global trade policy cooperation is derived as $W W=\frac{297+6 a+97 a^{2}}{200 b}$, while the welfare of the large country $(A)$ and the each small country ( $B$ or $C$ or $D)$ are respectively: $S W_{A}=\frac{183-46 a+263 a^{2}}{800 b}, \quad S W_{B}=S W_{B}=S W_{B}=\frac{201+14 a+25 a^{2}}{480 b}$. The intuition behind this result is that because each market is separated, the import tariff of each country does not provide the strategic protection effect for domestic industries. Therefore, the import subsidy is the best policy with the consumer surplus (CS) increase effect from the import subsidy dominant to the government surplus (GS) decrease effect from the subsidy.

For the global free trade regime under the unanimity rule to be sustained, the following self-enforcement condition should hold for each large and small country. Each country is assumed to take the trigger strategy. Then the self-enforcement

\footnotetext{
${ }^{8}$ The global trade policy cooperation can be reached through 6 consecutive bilateral trade agreements for free trade also. In this model, however, the bilateral agreement implies the partially cooperative trade regime to emphasize the structural difference between the global trade cooperation, multilateral cooperation and the partial cooperation.
} 
condition for the large country $(L)$ to keep the cooperative policy in an infinitely repeated trade policy game is given as follows:

$$
\text { IC for } \mathrm{L}: W_{L}\left(t_{A}^{D}, t_{B}^{C}, t_{C}^{C}, t_{D}^{C}\right)+\sum_{\tau=1}^{\infty} \delta_{L}^{t} W_{L}\left(t_{A}^{N}, t_{B}^{N}, t_{C}^{N}, t_{D}^{N}\right) \leq \sum_{\tau=0}^{\infty} \delta_{L}^{t} W_{L}\left(t_{A}^{C}, t_{B}^{C}, t_{C}^{C}, t_{D}^{C}\right)
$$

The first term on the right hand side of $L$ 's self-enforcement condition, (5), represents the one-period deviation payoff from the cooperative policy, while the second term represents $L$ 's social welfare when all the other countries retaliate with the non-cooperative tariffs from the next period. The right hand side of condition (5) represents the discounted social welfare when all the countries abide by the cooperative trade policies. The maximum deviation payoff for $L$ is attained when $L$ takes the non-cooperative Nash strategy while all the other countries abide by the cooperative policy, which reaches to $\frac{9801-297 a+11446 a^{2}}{36300 b}$, and the minimum payoff to $L$ from the cooperative strategy is given as $\frac{183-46 a+263 a^{2}}{800 b}$. Therefore, the incentive compatibility condition for $L$ can be expressed as:

$$
\frac{9801-297 a+11446 a^{2}}{36300 b}+\frac{\delta_{L}}{1-\delta_{L}} \frac{3\left(2+33 a^{2}\right)}{242 b} \leq \frac{1}{1-\delta_{L}} \frac{183-46 a+263 a^{2}}{800 b}
$$

The above incentive compatibility condition for the large country, $L$, which is country $A$, is reduced to as follows:

$$
\Rightarrow \quad \delta_{L} \geq d_{1}=\frac{3901 a^{2}-14322 a-11979}{27232 a^{2}+2376 a-71208}
$$

In the same way, the self-enforcement condition for a small country, $S$, comes as follows ${ }^{9}$ :

$$
\begin{gathered}
\text { IC for S: } W_{S}\left(t_{A}^{C}, t_{B}^{D}, t_{C}^{C}, t_{D}^{C}\right)+\sum_{\tau=1}^{\infty} \delta_{S}^{t} W_{S}\left(t_{A}^{N}, t_{B}^{N}, t_{C}^{N}, t_{D}^{N}\right) \leq \sum_{\tau=0}^{\infty} \delta_{S}^{t} W_{S}\left(t_{A}^{C}, t_{B}^{C}, t_{C}^{C}, t_{D}^{C}\right) \\
\Rightarrow \quad \frac{16572+2321 a+2057 a^{2}}{36300 b}+\frac{\delta_{S}}{1-\delta_{S}} \frac{103+2 a^{2}}{242 b} \leq \frac{1}{1-\delta_{S}} \frac{201+14 a+25 a^{2}}{480 b}
\end{gathered}
$$

\footnotetext{
${ }^{9}$ Among three symmetric small countries, $B, C$, and $D$, we check the case of country $B$ in checking the self-enforcement condition for the small countries. However, it does not cause any change if we check the case with country $C$ or $D$.
} 
The above incentive condition for a small country, $S$, is reduced to:

$$
\delta_{S} \geq d_{2}=\frac{10971+10098 a+1331 a^{2}}{8976+18568 a+14056 a^{2}}
$$

For the global trade policy cooperation to be sustained, the self-enforcing condition for $L$ and $S$ should hold simultaneously.

\subsection{The multilateral negotiation equilibrium under the consensus rule}

Now, we check the case of multilateral negotiation under the consensus rule where the cooperative trade agreement can be reached when at least the large economy, i.e., country $A$, and two of small countries ( $B$ and $C$ for example) reach at an agreement. The equilibrium tariffs and the output amounts of the representative firm are derived by the backward induction as in the earlier case. In this case, the cooperative tariff for the countries who cooperate such as country $A, B, C$ under consensus rule is: $(2+a) / 51$, while the optimal tariff of the country $D$, who does not join the coordination is $3 / 11$, which is same as the non-cooperative tariff level. By substituting the equilibrium output levels and the tariffs into the social welfare function of each country, which is composed of consumer surplus, producer surplus, and the government surplus, country $A, B, C$ and $D$ 's welfare are obtained as follows: the large country (A)'s social welfare: $S W_{A}=\frac{69602+6776 a+339647 a^{2}}{925650 b}, B$ and C's welfare: $S W_{B}=S W_{C}=\frac{384686-2662 a+34001 a^{2}}{925650 b}$,

D's welfare: $S W_{D}=\frac{227591-5632 a+17666 a^{2}}{476850 b}$, and the world welfare: $W W=\frac{2419229-17908 a+834779 a^{2}}{1748450 b}$.

The multilateral trade policy cooperation under the consensus rule is sustainable when the following incentive compatibility condition is held. ${ }^{10}$

\footnotetext{
10 The maximum deviation payoff for $L$ under multilateral negotiation is attained when $\mathrm{L}$ takes the deviation strategy while all the other countries abide by the cooperative policy, which reaches to $1199206-90992 a+6439411 a^{2}$ 


$$
\begin{gathered}
\text { IC for L: } W_{L}\left(t_{A}^{D}, t_{B}^{C}, t_{C}^{C}, t_{D}^{N}\right)+\sum_{\tau=1}^{\infty} \delta_{L}^{t} W_{L}\left(t_{A}^{N}, t_{B}^{N}, t_{C}^{N}, t_{D}^{N}\right) \leq \sum_{\tau=0}^{\infty} \delta_{L}^{t} W_{L}\left(t_{A}^{C}, t_{B}^{C}, t_{C}^{C}, t_{D}^{N}\right) \\
\Rightarrow \frac{1199206-90992 a+6439411 a^{2}}{15736050 b}+\frac{\delta_{L}}{1-\delta_{L}} \frac{3\left(2+33 a^{2}\right)}{242 b} \leq \frac{1}{1-\delta_{L}} \frac{69602+6776 a+339647 a^{2}}{925650 b}
\end{gathered}
$$

The incentive compatibility condition for $L$, i.e., country $A$, to keep the cooperative trade policy is reduced to the following condition:

$$
\Rightarrow \quad \delta_{L} \geq d_{3}=-\frac{44(71 a-11)^{2}}{124726+68728 a+1924021 a^{2}}
$$

The above self-enforcement condition holds always because the discount factor for $L$ is assumed to be non-negative. It means that under multilateral negotiation, the large country has no incentive to deviate from the cooperative trade policy. The intuition behind this result is that under the assumption of separated markets, the tariff has no strategic effect in protection for domestic producers. Therefore, under the consensus rule, the deviation payoff is not high enough to induce the deviation because one small country, $D$, is already left out of the policy coordination. Therefore, the large country has an incentive to keep the cooperative trade policy always.

In the same way, the self-enforcement condition for a small country, $B$, comes as follows:

$$
\begin{gathered}
\text { IC for S: } W_{S}\left(t_{A}^{C}, t_{B}^{D}, t_{C}^{C}, t_{D}^{N}\right)+\sum_{\tau=1}^{\infty} \delta_{S}^{t} W_{S}\left(t_{A}^{N}, t_{B}^{N}, t_{C}^{N}, t_{D}^{N}\right) \leq \sum_{\tau=0}^{\infty} \delta_{S}^{t} W_{S}\left(t_{A}^{C}, t_{B}^{C}, t_{C}^{C}, t_{D}^{N}\right) \\
\Rightarrow \quad \frac{1421195-28072 a+116402 a^{2}}{3147210 b}+\frac{\delta_{S}}{1-\delta_{S}} \frac{103+2 a^{2}}{242 b} \leq \frac{1}{1-\delta_{S}} \frac{384686-2662 a+34001 a^{2}}{925650 b}
\end{gathered}
$$

The above incentive condition for $\mathrm{S}$ under multilateral negotiation is reduced to: $\quad \delta_{S} \geq d_{4}=\frac{33(131-11 a)^{2}}{40\left(10210-3509 a+11299 a^{2}\right)}$

For the multilateral trade policy cooperation to be sustained, the self-enforcing condition for $L$ and $\mathrm{S}$ should hold simultaneously. However, as the self-enforcing condition of $\mathrm{L}$ always holds, the probability for the multilateral cooperation is much higher than the case of global trade policy cooperation. 


\subsection{Bilateral negotiation equilibrium}

Finally, the case of bilateral negotiation is examined. To evaluate the welfare effect of bilateral agreement, the welfare effect and the self-enforcing condition is checked from the perspective of small country and the large country. First, we check the case when the small country, $B$ negotiates with a large country, $A$, bilaterally, and the self-enforcement condition for $B$ to cooperate with $A$. In this bilateral agreement between $A$ and $B$, the optimal tariff is $(1+a) / 10$, which is higher than the multilateral negotiation case $((2+a) / 51)$, and much higher than the global free trade case. Then, $A$ 's welfare level from the bilateral trade policy coordination with country $B$ is: $S W_{A}=\frac{4299+1210 a+47311 a^{2}}{121000 b} \cdot B$ 's welfare under bilateral agreement with $A$ is: $S W_{B}=\frac{49311+1210 a+2299 a^{2}}{121000 b}$. Then the welfare level for small countries, $C$ and $D$, which are left out of policy cooperation, is: $S W_{C}=S W_{D}=\frac{67239-3872 a+4114 a^{2}}{151250 b}$.

The bilateral trade policy cooperation between a large economy and the small country is sustainable when the following incentive compatibility condition is satisfied. ${ }^{11}$

$$
\begin{gathered}
\text { IC for L: } W_{L}\left(t_{A}^{D}, t_{B}^{C}, t_{C}^{N}, t_{D}^{N}\right)+\sum_{\tau=1}^{\infty} \delta_{L}^{t} W_{L}\left(t_{A}^{N}, t_{B}^{N}, t_{C}^{N}, t_{D}^{N}\right) \leq \sum_{\tau=0}^{\infty} \delta_{L}^{t} W_{L}\left(t_{A}^{C}, t_{B}^{C}, t_{C}^{N}, t_{D}^{N}\right) \\
\Rightarrow \frac{1791+12694 a+41503 a^{2}}{121000 b}+\frac{\delta_{L}}{1-\delta_{L}} \frac{3\left(2+33 a^{2}\right)}{242 b} \leq \frac{1}{1-\delta_{L}} \frac{4299+1210 a+47311 a^{2}}{121000 b}
\end{gathered}
$$

The incentive compatibility condition for $L$, i.e., country $A$, to keep the cooperative trade policy is reduced to the following condition:

$$
\Rightarrow \quad \delta_{L} \geq d_{5}=-\frac{132\left(19-87 a+44 a^{2}\right)}{4791+12694 a+91003 a^{2}}
$$

The above self-enforcement condition holds always because the discount factor for $L$ is assumed to be non-negative. It means that under bilateral negotiation, the large country has no incentive to deviate from the cooperative trade policy. The critical value

\footnotetext{
11 The maximum deviation payoff for $L$ under bilateral negotiation is obtained when $L$ takes the deviation strategy, which is non-cooperative tariff at the level of $3 \mathrm{a} / 1 \mathrm{l}$ while country $B$ abides by the cooperative tariff policy, $(1+a) / 10$.
} 
of discount factor supports the self-enforcing condition for the large country always. Therefore, it is not requited to compare the critical value of discount factor between the multilateral negotiation and the bilateral negotiation regime. However, as shown in next section, the welfare level for the large country in bilateral negotiation is higher than the case of bilateral negotiation, and this welfare dominance of bilateral negotiation regime for the large country is reflected in the lower critical value of the discount factor which supports the self-enforcement condition.

In the bilateral negotiation regime, the self-enforcement condition for a small country, $B$, comes as follows:

$$
\begin{aligned}
& \text { IC for S: } W_{S}\left(t_{A}^{C}, t_{B}^{D}, t_{C}^{N}, t_{D}^{N}\right)+\sum_{\tau=1}^{\infty} \delta_{S}^{t} W_{S}\left(t_{A}^{N}, t_{B}^{N}, t_{C}^{N}, t_{D}^{N}\right) \leq \sum_{\tau=0}^{\infty} \delta_{S}^{t} W_{S}\left(t_{A}^{C}, t_{B}^{C}, t_{C}^{N}, t_{D}^{N}\right) \\
& \Rightarrow \quad \frac{59343-7106 a+3751 a^{2}}{121000 b}+\frac{\delta_{S}}{1-\delta_{S}} \frac{103+2 a^{2}}{242 b} \leq \frac{1}{1-\delta_{S}} \frac{49311+1210 a+2299 a^{2}}{121000 b}
\end{aligned}
$$

The above incentive condition for $S$ under bilateral negotiation is reduced to:

$$
\delta_{S} \geq d_{6}=\frac{132\left(76-63 a+11 a^{2}\right)}{7843-7106 a+2751 a^{2}}
$$

The comparison of the critical values of the small country's discount factor supporting the self-enforcement condition between bilateral negotiation regime and multilateral negotiation regime provides an ambiguous result, with the critical value in bilateral negotiation regime being lower than that in the multilateral negotiation regime when the value of $a$ is larger, i.e., when the market size difference between the large country and the small country becomes bigger. This result is consistent with the intuition that with the bigger market size difference, it is more likely that the small country complies with the large country in the bilateral trade negotiation regime.

\section{The optimal trade negotiation strategies}

To determine the optimal negotiation strategies of each country, we compare the welfare levels of the large economy ( $A$ as $L$ ) and the small economy in four different trade negotiation regimes. The welfare levels of the large country from four types of 
trade regimes are as follows:

A large country $(A)$ 's welfare:

i) $W_{A}$ (global trade warfare): $\frac{3\left(2+33 a^{2}\right)}{242 b}$ (the non-cooperative Nash equilibrium regime)

ii) $W_{A}$ (global trade cooperation): $\frac{183-46 a+263 a^{2}}{800 b}$

iii) $W_{A}$ (multilateral trade cooperation): $\frac{69602+6776 \mathrm{a}+339647 \mathrm{a}^{2}}{925650 \mathrm{~b}}$

iv) $W_{A}$ (bilateral trade cooperation): $\frac{4299+1210 \mathrm{a}+47311 \mathrm{a}^{2}}{121000 \mathrm{~b}}$

From this comparison, it is found that in case of the large economy, $A$, the welfare level under the bilateral trade cooperation is always welfare dominant to the multilateral trade policy cooperation: $W_{A}$ (bilateral trade cooperation) - $W_{A}($ multilateral trade cooperation $)=\frac{-734293+49610 \mathrm{a}+445643 \mathrm{a}^{2}}{18513000 \mathrm{~b}}>0$ when $a>1$.

In addition, from the comparison between ii) and iv), it is found that only when the market size difference is not so large, the global trade cooperation is welfare dominant for the large economy. However, when the market size difference is large, the large economy prefers the bilateral agreement to the global cooperation. That is, the large country's welfare from the global cooperation is superior to the bilateral trade cooperation only when the market size difference is not so large:

$W_{A}($ globaltradecooperation $)>W_{A}$ (bilateraltradecooperation) only when $1<a<1.30117$.

When we compare $W_{A}$ (global trade warfare) and $W_{A}$ (global trade cooperation), it is found that the global trade policy cooperation provides a higher welfare level to the large country than the global trade warfare only when the market size difference is relatively small: $W_{A}$ (global trade cooperation $)>W_{A}($ global trade warfare) only when $1<$ $\mathrm{a}<1.27515$. In addition, it is found that the large country $(A)$ prefers the bilateral agreement to the trade warfare when $A$ 's market size is close to those of the small countries: $W_{A}$ (bilateral trade cooperation $)>W_{A}$ (global trade warfare) when $1<\mathrm{a}<$ 1.0948. However, when the market size difference is relatively large, the large country 
$(L)$ prefers the trade warfare: $W_{A}($ bilateral trade cooperation $)<W_{A}($ global trade warfare $)$ when a $>1.0948$.

The above results show that with the relatively big market-size difference, the large country prefers the non-cooperative trade policies to cooperative policies. Among cooperative policies, the large country prefers the bilateral trade negotiation regime than the multilateral trade cooperation. Within the multilateral trade cooperation, the large country prefers the global trade cooperation with the unanimity rule to the multilateral cooperation with the consensus rule only when the market size difference is relatively small: $W_{A}$ (global trade cooperation) $>W_{A}$ (multilateral trade cooperation) when a $<$ 1.32888. In summary, it has been found that when the market size difference is relatively large, the large country prefers non-cooperative trade policy regime, and among trade policy cooperation, $L$ prefers more limited level of cooperation. The intuition behind this result is that $L$ can command larger market power in non-cooperative trade regime. ${ }^{12}$ In a cooperative trade regime, $L$ can command larger market power with policy cooperation with smaller number of countries than the case with larger number of countries.

On the other hand, the small country's welfare levels from different regimes of trade policy negotiation come as follows.

Small country $(B)$ 's welfare levels:

i) $W_{B}($ global trade warfare $): \frac{103+2 \mathrm{a}^{2}}{242 \mathrm{~b}}$

ii) $W_{B}$ (global trade cooperation): $\frac{201+14 \mathrm{a}+25 \mathrm{a}^{2}}{480 \mathrm{~b}}$

iii) $W_{B}$ (multilateral trade cooperation): $\frac{384686-2662 \mathrm{a}+34001 \mathrm{a}^{2}}{925650 \mathrm{~b}}$

iv) $W_{B}$ (bilateral trade cooperation with the large economy):

\footnotetext{
12 In other words, the non-cooperative trade regime provides the large country with a larger room for the strategic behaviors while it needs not worry about the possible prisoners' dilemma due to the large market size difference when the value of $a$ is relatively large. The same logic applies to the result that the welfare level of the large country is higher in a cooperative trade regime with a smaller number of countries.
} 
For a small country, $S$, the global trade cooperation with the unanimity rule is always preferred to the global non-cooperative trade warfare: $W_{B}$ (global trade

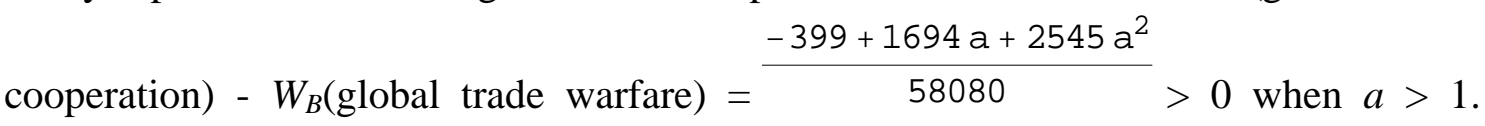
Among the cooperative trade policy regimes, the welfare level for the small country from the global trade cooperation with the unanimity rule is always dominant to that from the multilateral trade cooperation with the consensus rule: $W_{B}$ (global trade cooperation with the unanimity rule) $-W_{B}$ (multilateral trade cooperation with the consensus rule $)=\frac{46879+474562 \mathrm{a}+227359 \mathrm{a}^{2}}{14810400 \mathrm{~b}}>0$ when $a>1$. Finally, it is found that the small country always prefers the multilateral trade cooperation to the bilateral trade cooperation with the large country: $W_{B}$ (multilateral trade cooperation) $-W_{B}$ (bilateral trade cooperation with $\mathrm{B})=\frac{149137-238370 \mathrm{a}+328273 \mathrm{a}^{2}}{18513000 \mathrm{~b}}>0$ when $a>1$.

The above results show that it is always preferable for the small country to cooperate with as many countries as possible while for the large country, it is preferable to cooperate with smaller number of countries.

In addition, there are two ways to reach an agreement of global cooperation, i.e., i) the sequential bilateral negotiation for trade cooperation, and ii) multilateral negotiation for trade cooperation from the initial stage. The above results imply that for a small country, the optimal dynamic process to reach at global trade cooperation is the multilateral negotiation from the initial stage, while the optimal dynamic process is a sequential bilateral negotiation for the large country.

From the comparison of two negotiating regimes' incentive compatibility conditions for a large country to abide by the trade policy cooperation, it turns out that it is more likely that the large country keeps the trade policy cooperation under the multilateral trade policy cooperation regime under the consensus rule than the case of global policy cooperation with the unanimity rule: $d_{1}>d_{3}$ where $d_{1}$ is the critical value of the discount factor for the self-enforcement condition for the large economy in the 
global trade cooperation with the unanimity rule while $d_{3}$ is the critical value of the discount factor for the self-enforcement condition for the large economy in the multilateral trade cooperation with the consensus rule, which turned out to be negative value.

However, for a small country, the trade policy cooperation is more probable under the global trade cooperation with the unanimity rule than under the multilateral cooperation with the consensus rule when the market size difference is relatively small: $d_{4}>d_{2}$ when $a<1.285$. However, when the market size difference is relatively large, it is more likely that the small country abides by the cooperative policy under the multilateral cooperation regime with the consensus rule than under the global cooperation regime with the unanimity rule: $d_{4}\left\langle d_{2}\right.$ when $a>1.285$. The intuition behind this result is that when the market size difference is relatively large, the small country recognizes that the big country is less likely to cooperate in the global trade cooperation with the unanimity rule, and more likely to cooperate under the multilateral cooperation regime with the consensus rule. Therefore, when the market size difference is relatively large, it is more likely that the small country complies with the large country under the multilateral cooperation regime with the consensus rule rather than under the global trade cooperation with the unanimity rule. ${ }^{13}$

\section{Concluding remarks}

Based on a model assuming linear demand functions and the separated market assumptions, it has been found that the country with a large market size prefers the ry non-cooperative trade policy regime because of the increased market power enabled by the non-cooperative trade policy regime. Therefore, as the dynamic negotiation strategy

\footnotetext{
${ }^{13}$ This result is consistent with the earlier result we obtained from the comparison of $d_{2}$ and $d_{4}$, which shows that it is more likely that the small country complies with the large country in the bilateral trade negotiation regime compared to the multilateral negotiation regime with the bigger market size difference.
} 
leading to the global cooperation, the sequential bilateral negotiation strategy is the welfare dominant negotiation strategy for the large economy. However, for a small economy, it has been shown that the cooperative trade regime with a larger number of countries provides higher welfare. Therefore, the optimal negotiation strategy for a small economy toward the global trade cooperation is to pursue the multilateral negotiation with as many negotiating countries as possible from the initial stage of the negotiation.

The above results provide several policy implications on DDA negotiation strategies. In the negotiation of market opening for agricultural commodities and service markets, the country with little market power should avoid the interim bilateral negotiation. In the actual experience of WTO negotiation, it has been observed that "the green room negotiation" between a few major stakeholders is the engine of multilateral negotiation. In other words, the bilateral negotiation or the negotiation between limited number of countries is the major means to reach at a multilateral negotiation in reality. In this context, the country with little market power in the negotiation agenda should minimize the chances for the green room negotiation. In stead, those countries with small market size should resort to the multilateral negotiation, and coalition formation strategy if available from the initial stage of the WTO negotiation.

The model in this paper can be extended to introduce the asymmetry between the negotiation countries such as in discount factors reflecting the asymmetry in negotiation power in addition to the disagreement payoffs. The technology differences between the negotiating parties and incomplete information in multilateral negotiation are also important factors characterizing the negotiation strategies in multilateral negotiation. These issues should be addressed in the future studies.

\section{References}

Bac, M and H. Raff, (1997) A theory of trade concessions. Journal of International 
Economics 42: 483-504.

Bagwell, Kyle; Staiger, Robert (1990) A Theory of Managed Trade, American Economic Review 80: 779-95.

Baliga, Sandeep (1995) Multilateral bargaining with Imperfect Information, Journal of Economic Theory 67, p. 578-589.

Bennett, Elaine (1997) Multilateral Bargaining Problems, Games and Economic Behavior 19, pp. 151-179.

Conconi, Paola \& Carlo Perroni (2002) Issue Linkage and issue tie-in multilateral negotiations, Journal of International Economics 57, pp. 423-447

Dixit, Avinash (1987) Strategic Aspects of Trade Policy, Advances in economic theory: Fifth World Congress, pp.329-62.

Feenstra, Robert \& T. Lewis, Negotiated Trade Restrictions with Private Political Pressure, Quarterly Journal of Economics, Volume 106, Issue 4, pp. 1287-1307.

Furusawa, T. (1999) The negotiation of sustainable tariffs, Journal of International Economics 48: 321-345.

Hoekman, B. and M. Kostecki (2001) The Political Economy of the World Trading System, Oxford: Oxford University Press.

Hungerford, Thomas (1991) GATT: A Cooperative Equilibrium in a Noncooperative Trading Regime?, Journal of International Economics, Volume 31, Issue 3-4, pp. 357-369.

Jensen, Richard \& M. Thursby (1988) Tariffs with Private Information and Reputation, Journal of International Economics, Volume 29, Issue 1-2, pp. 43-67.

Kennan, John \& R. Riezman, Do Big Countries Win Tariff Wars?, International Economic Review, Volume 29, Issue 1, February 1988, pp. 81-85.

Kovenock, Dan \& M. Thursby (1992) GATT, Dispute Settlement and Cooperation, Economics and Politics 4: 151-170.

Krishna, Vijay \& R. Serrano (1996) Multilateral Bargaining, Review of Economic Studies 63, p. 61-80.

Maggi, Giovanni (1999) The role of multilateral institutions in International trade cooperation, The American Economic Review 89, n. 1. pp.190 - 214.

Mayer, W. (1981) Theoretical Considerations on Negotiated Tariff Adjustments, Oxford Economic Papers 33: 135-53.

McCalman, P. (2002) Multi-lateral trade negotiations and the Most Favored Nation clause, Journal of International Economics 57, Issue 1: 151-176. 
McLaren, J. (1997) Size, sunk costs and Judge Bowker's objection to free trade, American Economic Review 87: 400-421.

Nash, John (1950) The Bargaining Problem, Econometrica 18: 155-162.

Park, J. (2000) International Trade Agreements Between Countries of Asymmetric Size," Journal of International Economics Vol. 50, pp. 473-95

Riezman, Raymond (1991) Dynamic Tariffs with Asymmetric Information, Journal of International Economics v30, n3-4, pp.267-83.

Rubinstein, A. (1982) Perfect equilibrium in a bargaining model, Econometrica 50, pp. 97-109. 